\title{
On the antifragility of cities and of their buildings
}

\author{
Ivan Blečić ${ }^{*}\left(\mathbb{D}\right.$ and Arnaldo Cecchini ${ }^{2}$
}

\begin{abstract}
We discuss the relevance of the concept of antifragility, introduced by Nassim Taleb, to the theory and practice of urban planning and design. We further contrast the antifragility of cities with that of their "smartness", suggesting that the former deserves a greater focus in the planning practice. Finally, we explore the potential antifragility of buildings, arguing it to be an important factor of the antifragility of cities in general.
\end{abstract}

Keywords: Antifragile planning, Antifragile urbanism, Urban design

\section{Introduction}

We want to present arguments why we hold it useful, for the practitioners and scholars who deal with the difficult practice of planning and urban design, to talk about antifragile city.

To do that, we will start by presenting the general concept of antifragility, and then talk about the antifragility of cities in particular. Next we will explore what an antifragile planning might be and look like. In a brief detour we will discuss the concept of so called "smart cities", to see if the focus on promoting the antifragility of cities, rather than their "smartness", may prove to be a more appropriate and worthwhile goal for public policies and planning. Finally we will examine how the many lives of buildings may become a source of inspiration for good designs, projects and plans. All in all, we will suggest that a useful way to design buildings and to plan cities (and to plan buildings and to design cities) is first of all to explore what makes them fragile, robust (or resilient) and antifragile, in order to build them to last, by making them capable to transform, adapt, and improve with time.

\section{On the fragility, robustness, resilience, and antifragility of things}

The concept of antifragility was proposed by Nassim N. Taleb in his 2012 book "Antifragile: things that gain from disorder", on which we abundantly draw in the following discussion.

\footnotetext{
${ }^{*}$ Correspondence: ivanblecic@unica.it

1 Department of Civil and Environmental Engineering and Architecture, University of Cagliari, Via Marengo 2, 09123 Cagliari, Italy

Full list of author information is available at the end of the article
}

To clarify the distinction between the fragility, robustness, and antifragility of things, let us begin with the obvious observation that all kinds of perturbations and unpredictable events take place around (or within) them. If these perturbations can only harm, damage or break the object, then the object is fragile. Give it enough time, and a perturbation of a sufficient magnitude will eventually occur to damage or break it. A fragile object is an object likely to get damaged or to break with time.

To follow Taleb, there is a useful operational test to distinguish a fragile, from a robust, from an antifragile physical object: it is to imagine what you would write on a parcel if you had to ship that object by a postal service.

If the label you put is "Fragile. Handle with care", then the object is fragile, and indeed the handling instructions provide us a reasonably accurate operational definition of fragility. Take a porcelain cup as an example. There is plainly no event the cup can benefit from, and even if the majority of events do not harm it, give it enough time and something will eventually happen to break the cup. This apparently simple observation on the property of fragility of things brings along a fundamental epistemic implication: we cannot predict exactly what will break the cup and when will it break it, but what we do know is that, give it enough time, and something will damage, and eventually break it. That much we can predict.

So, something is fragile if events, perturbations, volatility, disorder-that is to say, time-can only harm it. 
Now, what is the opposite of fragile? Many words come to mind: hard, robust, resistant, resilient...But, to follow Taleb, none of these is exactly right: none is the strict opposite of fragile.

An anvil for example is a robust thing. Indeed, what would you write on the parcel if you had to ship it? Nothing, in fact: whatever occurs to it, nothing happens to it, weather you kick it, throw it, or shake it. Every robust thing is of course robust up to a point (anvils melt above certain temperature), but in general we can say that almost nothing can harm a robust object. But also nothing can benefit it.

So, something is robust if events, perturbations, volatility, disorder-that is to say, time-cannot harm, nor can they benefit it. And if we think carefully, that is not exactly the opposite of fragile.

This, by the way, is true even if we use the term "resilient" instead of "robust". After all, resilience is the capacity of a material, or in our case of an object, to absorb a shock without breaking, perhaps deforming but then rebounding to its previous state or condition. Even in biology, the use of resilience does not offer us other than the speed with which a biotic community is able to recover its stability after being exposed to perturbations.

Therefore, in the case of resilience as well as robustness, the time, though in different ways, ultimately leaves the object or the system unchanged. (This, we will see, have some implications for the use of the idea resilience in planning.)

So, to come back to our original question, something that has a property opposite to fragile should not only remain unharmed (and unchanged) by the perturbations and by the passage of time; rather it should sometimes also improve and benefit from the disorder. If such a thing existed, and we had to ship it by postal service, we would write on the parcel "Antifragile. Mishandle carelessly", because such things or systems would be able to benefit from events, perturbations, volatility, disorderthat is to say, from time.

Are there things that are antifragile in this precise sense? Well, many things (organisms, systems) are, at least on a relevant time scale. For example life on Earth with its biological evolution is quintessentially antifragile, and our body, for many aspects and within the horizon of one's life, is antifragile. All the living organisms are generally (again, to a certain extent and within their life cycle) antifragile, as are many objects, technologies, institutions, social practices and systems which last for a long time. The very fact of being "old" is often itself a proof of their antifragility, for they wouldn't be around for a long time without being antifragile.

For human-designed systems, think of the air transportation and its evolution: the system is designed to learn from errors and improve on itself, so every glitch, mishap or disaster makes the system safer and more reliable. Or think of the anecdote when after France took Pope Pius VII prisoner, Napoleon erupted in one of his rants, telling the Secretary of State, Cardinal Ercole Consalvi, that he will "crush" the Roman Catholic Church. The Cardinal glumly shrugged at the Emperor: "If in 1800 years we clergy have failed to destroy the Church, do you really think that you'll be able to do it?"

Finally, think of the city, which as a general form of human settlement is (as we shall see) antifragile, and think of some cities in particular, of parts of cities, and of buildings which (we shall see) may also be antifragile.

To appreciate the breath of the concept, let us closely read the beginning of Taleb's prologue on antifragility:

Some things benefit from shocks; they thrive and grow when exposed to volatility, randomness, disorder, and stressors and love adventure, risk, and uncertainty. Yet, in spite of the ubiquity of the phenomenon, there is no word for the exact opposite of fragile. Let us call it antifragile.

Antifragility is beyond resilience or robustness. The resilient resists shocks and stays the same; the antifragile gets better. This property is behind everything that has changed with time: evolution, culture, ideas, revolutions, political systems, technological innovation, cultural and economic success, corporate survival, good recipes [...], the rise of cities, cultures, legal systems, equatorial forests, bacterial resistance... even our own existence as a species on this planet. And antifragility determines the boundary between what is living and organic (or complex), say, the human body, and what is inert, say, a physical object like the stapler on your desk.

The antifragile loves randomness and uncertainty, which also means-crucially-a love of errors, a certain class of errors. Antifragility has a singular property of allowing us to deal with the unknown, to do things without understanding them-and do them well. Let me be more aggressive: we are largely better at doing than we are at thinking, thanks to antifragility. I'd rather be dumb and antifragile than extremely smart and fragile, any time (Taleb 2012, pp. 21-22).

\section{On the antifragility of cities, and on their many lives}

With Harvey, we like to remember Park's words:

"[The city is] man's most successful attempt to remake the world he lives in more after his heart's 
desire. But, if the city is the world which man created, it is the world in which he is henceforth condemned to live. Thus, indirectly, and without any clear sense of the nature of his task, in making the city man has remade himself" (Harvey 2008).

The City-with the capital $\mathrm{C}$, as the general form of human settlement, as the ecological niche of our species-belongs to the world of antifragility. It is a system that has proven through history to be capable to adapt, self-organise, improve and take advantage of the unpredictable, in short to prosper in disorder. Not only does the City exist for ten thousands years; not only is our culture predominantly a product of City; But also the majority of the human population lives in cities and the trends are that of a further consistent and rapid increase of urban population. ${ }^{1}$

This of course does not ensure that the City will have a happy future, or a future tout court. And this does not tell us much about the destiny of single cities (with the lowercase c), whose life as "individuals" is much shorter than that of the City as "species".

A fascinating example we like to mentions is the city of Split in Dalmatia, also in relation to an interesting book The Split Case (Radović et al. 2012). ${ }^{2}$ The nowadays Split-which has developed through a numerous historical and physical stratifications (Fig. 1) starting from a single "building", the Diocletian's Palace in Dalmatia-stands there to testify how the free actions of inhabitants, and the "autonomous" evolution of buildings, tend towards reuse and reinvention (Wolfe 2012): we can learn from Split also when we design in a deliberate and mindful way.

The urban evolution of Split may be put alongside another almost converse evolution, that of the city of Arles (Fig. 2): at one point in its history, the city theatre, once within the city, becomes the city's boundary, hosting the entire city within itself, this time due to a deliberate decision.

\section{On why we shouldn't really call cities smart}

Let us make a brief detour on the concept of "smartness" from the perspective of antifragility, all the more befitting since the concept has of late become rather fashionable in the debates on urban planning and design.

\footnotetext{
${ }^{1}$ See http://esa.un.org/unpd/wup/highlights/wup2014-highlights.pdf.

2 "This book is about one particular city, about the cities in general, and about the ways to approach the urban. The main aim behind its production was to present one authentic urban practice, hypothesizing how unique practices demand authentic methods capable to simultaneously address times and spaces, the glamour and the everydayness of the urban." (book back cover).
}

As one can gather from the ending of the previous quote from Taleb, there is one important difference between antifragility and smartness: something can be antifragile without being smart, without intentionality, also "by chance".

Indeed, can an object or a system devoid of intentionality and incapable of design be called smart or intelligent at all? In a sense, the evolution constitutes an example of a behaviour that "works". But, should we call a thing that works smart, rather than, say, fit? Should the effect of a thing that works be called smart adaptation, rather than simply the survival of the fittest? For intelligence and smartness always require design and the intentionality that comes with it (Blecic and Cecchini 2008), so that we are authorised to talk of smart urban planning and design, but not of smart city.

We do not want to stand on ceremony too much: maybe we can only by extension admit to call smart objects and systems capable of reactions and responses which work, that is to say, those reactions and responses which allow objects and systems to continue to exist, to serve their function (be it designed or not), to grow and to reproduce, and so on; but other words are better, such as - antifragile.

Let us make a few friendly critical remarks on the concept of smart cities. It is not easy to understand what smart city exactly means: from the original meaning linked to a city with a heavy use of new technologies, the boundaries of what the concept should encompass have been progressively expanded. Daily, new things, technologies and practices get dubbed "smart", so is there hope ever to arrive at a certain stability of category?

But one should also ask: isn't this preoccupation with clear-cut definitions and delimitations, after all, a sterile academic exercise? Should we care? No it isn't and yes we should, and the reason for that has to do, as it were, with putting a certain genie back in the bottle.

But, of genies and bottles latter, let us first see what has been and is being said of the concept of smart city. For instance, for the Smart Cities Council, "a smart city is one that has digital technology embedded across all city functions". ${ }^{3}$ As the Council itself candidly admits on its website, here we're more or less as with pornography, "I know it when I see it."

Then there is the definition by Caragliu et al. (2009):

"A city can be defined as 'smart' when investments in human and social capital and traditional (transport) and modern (ICT) communication infrastructure fuel sustainable economic development and

\footnotetext{
${ }^{3}$ http://smartcitiescouncil.com/smart-cities-information-center/definitions-and-overviews.
} 

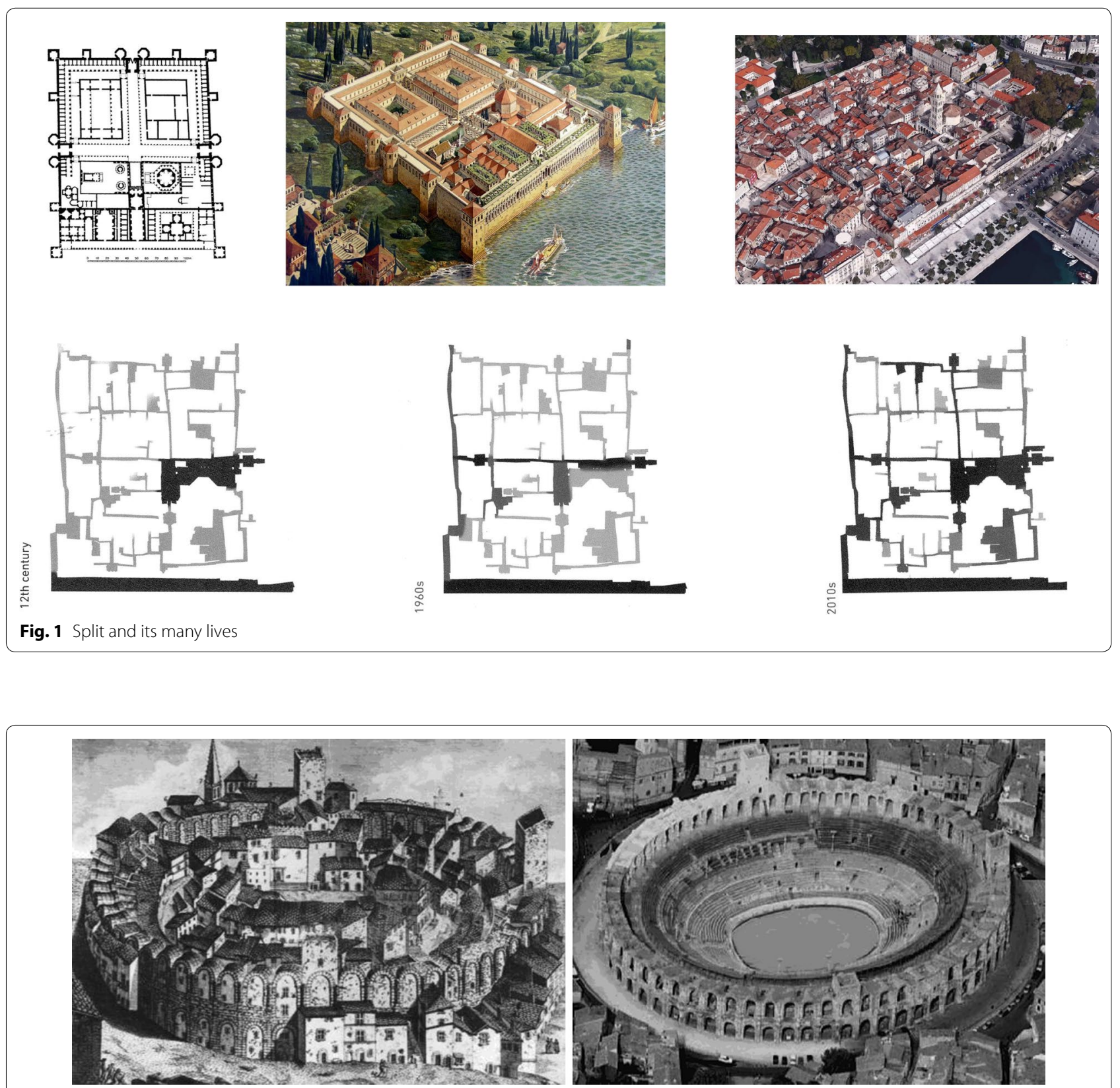

Fig. 2 The city of Arles

a high quality of life, with a wise management of natural resources, through participatory action and engagement."

There is a lot not to like in this definition. It appears extremely wide, its voracity swallowing almost everything, its vagueness deriving from references to other voracious concepts, like social capital, sustainability, participation, quality of life, wisdom, community, which, like parsley, are good to season almost every dish.
Let us now bring up a few passages from a Rem Koolhas talk in 2014 (Koolhas 2014):

The smart city movement today is a very crowded field, and therefore its protagonists are identifying a multiplicity of disasters which they can avert. The effects of climate change, an ageing population and infrastructure, water and energy provision are all presented as problems for which smart cities have an answer. Apocalyptic scenarios are managed and mitigated by sensor-based solutions. Smart cities 
rhetoric relies on slogans- $f i x$ leaky pipes, save millions.' Everything saves millions, no matter how negligible the problem, simply because of the scale of the system that will be monitored. The commercial motivation corrupts the very entity it is supposed to serve... To save the city, we may have to destroy it... When we look at the visual language through which the smart city is represented, it is typically with simplistic, child-like rounded edges and bright colours. The citizens the smart city claims to serve are treated like infants. We are fed cute icons of urban life, integrated with harmless devices, cohering into pleasant diagrams in which citizens and business are surrounded by more and more circles of service that create bubbles of control. Why do smart cities offer only improvement? Where is the possibility of transgression? And rather than discarding urban intelligence accumulated over centuries, we must explore how to what is today considered "smart" with previous eras of knowledge.

Here the nature of smart city as ideology proper arises. It comes as a no surprise that the global contagion has been underpinned by the very agents of global capitalism, with, among others, IBM, Siemens and Cisco as prime promoters, as it is well documented by Adam Greenfield in his 2013 book Against the smart city (Greenfield 2013). This is something that shouldn't be forgotten. As Greenfield lucidly puts it:

The enterprises enumerated here are to a surprisingly great degree responsible for producing both the technical systems on which the smart city is founded and the rhetoric that binds them together in a conceptual whole. While this may not be a particularly remarkable circumstance by the standards prevailing in industry, the deep involvement of large-scale commercial actors in the germination ideas about the design and equipment of cities does make it somewhat unusual in the history of urbanism. It's as if the foundational works on twentieth-century urbanist thought had been collectively authored by United States Steel, General Motors, the Otis Elevator Company and Bell Telephone rather than Le Corbusier or Jane Jacobs.

On the level of effectiveness, smart city, at least in some variants of its ideological use, may be seen as the regression to a naïve techno-positivism, and a distraction from thinking. Adam Greenfield's critique could be enough, but one thing has to be added more in general. It is telling that smart city, even as an academic endeavour, is often framed as providing "solutions" (often for optimisation and efficiency). This focus on "solutions" sounds much in the spirit of what we, at least in Europe, are being told academia should more and more become about, within the vast reforms of the university on the continental scale: instead of critical thinking-instead of an effort to provide not only answers, but also the right questionswe are progressively asked to be "useful" and to provide technical "solutions" to the messes of our neoliberal present and of our political and social predicament. So, for example, if there are violent unrests in the banlieues, we are called to train psychologists and sociologists to devise tools to calm people down, and urbanists to design neighbourhoods that would dissuade and impede outbursts of rebellion. Examples like this abound.

All these are reasons we do not like the expression "smart cities", or better-and this is our real point herewe do not like how the term has been appropriated. But we also think the solution isn't to abandon it. Rather, the point is to think more carefully about "smartness", to see its potentials, to re-appropriate it and put it into a wider debate on cities and how they could be planned, managed and governed. In a short formula: the point is to liberate the concept of smart city from its ideological horizon of meaning.

For that, we should care to better define and delimit the concept of "smartness". For that, let us again return to the question of definitions, to see if we can make some progress there.

One can stumble upon another more dynamic definition, from none other than the U.K. Government (2013), which sounds promising to us:

\section{"The concept is not static, there is no absolute defini- tion of a smart city, no end point, but rather a pro- cess, or series of steps, by which cities become more 'liveable' and resilient and, hence, able to respond quicker to new challenges".}

Here we have elements that recognize the important fact that cities as complex systems-as systems of systems (social, economical, geographical, ecological,...) have always had the capability to adapt and to improve, due to external and internal stressors, due to the variety and plurality of needs and desires of their inhabitants, users, social and economic subjects, using available technologies and information.

In this sense, not only does it appear to us inappropriate to call "smart" a city, especially is we talk about the smartness of things and not people (Ratti 2013), but it also appears to us insufficient to promote the mere "resilience" of cities. A complex system such as city cannot only limit itself to absorb or ward off blows: it ought to do more than just adapt, it needs to evolve, transform: redundancies, duplications, plasticity, exaptations, are all elements of an evolution which has enabled the city 
to survive and thrive for ten thousands years, and to evermore become the "ecological niche" of the human species.

Let us clear the air. We claimed that it is inappropriate, and may even be dangerous, to define smart a city. It seems to us better not to abuse of this expression. If we really need to talk about smartness, we should better talk about smart land (Bonomi and Masiero 2014) or about smart citizens (Ratti 2013; Hemment and Townsend 2013). Nonetheless-with many caveats we have expressed-even this fashionable expression may be of some usefulness.

But to us, a better and a more appropriate objective to set for a city and for its evolution is that of antifragility, we prefer the expression "antifragile city".

On this, one last clarification is due. Antifragility is not always and necessarily good in itself. There are fragile objects and systems which owe their beauty and raison d'être to their fragility; sometimes the fragility is pursued, just as the ephemeral and the perishing may be fascinating. Then there are robust things and systems which better be so, also for the reasons of economy and simplicity. Then there are resilient systems which function satisfactorily: strictly speaking, urban resilience is an essential mode of response to the catastrophic events and to the effects of climate change (Pickett et al. 2004; Musco and Zanchini 2014). All in all, there are many objects and subsystems within the city which are fragile, robust, resilient, and antifragile, all necessary for its survival and functioning.

\section{What is antifragile planning?}

Urban planning is a set of norms and tools whose purpose it to govern the city in view of a common vision. An antifragile planning is that which fosters the antifragility of a city. To be effective, planning should avoid fragilising the city, and should accompany and take advantage of its spontaneous dynamics ("Nature to be commanded must be obeyed").

To support the processes which make cities antifragile is the fundamental objective of antifragile planning: it means taking care of individual cities and of their destinies, and not only of the City in general.

A planning dependant on accurate predictions is fragile, since such forecasting on complex system is, strictly speaking, impossible. This is in particular true for social systems, which are twice complex: besides their "objective" complexity due to numerous non-linear interactions among its constitutive elements, they also contain agents capable of choice and-within limits-free to chose (Portugali et al. 2012).

But a planning that does not "tend towards a future" and does not aim at "producing a future", is a contradiction in terms. And it is not unreasonable to hold that a community wants and ought to think about its future, at least within an "imaginable" time horizon of three to four generations, and to try to avoid undesirable futures.

We have discussed the concept of antifragile planning at length in a recent book (Blečić and Cecchini 2016). Since the point of antifragile planning is not only about what to do, but also a lot about what better not to do, in the book we have identified factors and attitudes which make planning ineffective because they may fragilise the city:

1. Plans based on fragile predictions i.e. requiring accurate predictions obtained with forecast models highly sensitive to its parameters, and therefore themselves fragile. If a decision or an action is grounded on the high accuracy of a prediction, and the phenomenon (or the model used to simulate it) under scrutiny is highly sensible to small variations in the parameters, then the prediction is fragile, and therefore the decision and the action are themselves fragile.

2. Excess of centralisation especially if combined with the ambition to simultaneously micromanage the functioning of the system.

3. Efficiency and optimisation when they reduce optionality, trim protective safeguards and redundancies, reduce the possibility of exaptations and of accommodation of heterogeneity of ends and needs-present and future. In short: to be highly effective, the system must be somewhat inefficient.

4. Specialisation which makes the system fragile to external perturbations, and reduces its capability to learn and adapt to environmental change.

5. Excessive simplification which doesn't take into account the complexity and all the possible counterintuitive, feedback and autopoietic behaviours of the system.

6. Lack of consensus.

7. Inequality and inequity.

The last two fragilisers are not strictly derived from Taleb, but are rather inspired by Jared Diamond's fascinating book "Collapse" (Diamond 2005) on "how societies choose to fail or succeed". Amongst five categories of causes that could lead civilizations to a collapse, Diamond puts the lack of social cohesion. This is a noteworthy point in our discussion on planning since social cohesion should not be intended naively as a steady state of "harmony", but rather as a precarious and dynamic result of conflicts and negotiations. There has been cases in history of social cohesion assured by an authoritarian or tyrannical government, and we cannot exclude 
similar cases from happening in an age of post-democracy (Crouch 2004) or counter-democracy (Rosanvallon 2006). Though this awareness ought not inhibit us to think that a stable social cohesion may only be sustained by a substantial equality of rights and a reasonably fair distribution of benefits, wealth and power. The survival of the city can be assured, and conflicts can be managed only if - to some extent-the "right to the city" is assured to everybody and if-to some extent-the power is distributed among all the member of the political community.

These are matters for planning to deal with and therefore it first or all needs to build a shared vision, to identify which future scenarios to avoid, and those to seek for, as an effective strategic choice.

To pursue such a shared vision, the adopted plans and regulations must then grant the certainty of what is permitted and therefore must specify what is forbidden on the long run (this is what we can call the via negativa of antifragile planning). Finally, plans and regulations should allow for the free expression within the social forms they chose: this we can call the space of the project.

Let us mention a few specific aspects of such an antifragile planning, related to both the urbs and the civitas (Cecchini 2013).

The first is related to the large projects, the so called megaprojects. A megaproject is often entirely self-referential, its purpose largely being the megaproject itself. It is intrinsically fragile, since it is grounded on uncertain predictions and it exhibits a large and non-linear exposure to uncertainty (Ansar et al. 2016), even when the predictions are not manipulated (often costs and timelines are systematically underestimated, and benefits are systematically overestimated).

But there may also be large projects composed mainly of a multitude of small and medium works, distributed and reversible. For example, a project aimed at improving and connecting a distributed web of public spaces in a city-from the places for play, to the local markets, from the streets and their walkability usable for many types of mobility and for different functions, to the recovery of abandoned buildings - would be a large project capable of significantly improving the quality of life of millions of people, with actions and interventions each individually relatively modest and inexpensive, but of remarkable size and scope taken together.

What makes this kind of projects antifragile is that single interventions may be modular, distributed, reversible, taking advantage of the social practices on the ground. They of course require a coherent long-term plan, which however may be flexible and amendable precisely because it is composed of a bundle of actions each requiring modest effort, expenditure and time.
All this is pretty much in syntony with the practices of the so called tactical urbanism, which has been defined as «a city and citizen-led approach to neighbourhood building using short-term, low-cost and scalable interventions to catalyse long-term change» (Lydon and Garcia 2015). The mode of actions described by Lydon and Garcia is a set of techniques and tactics much befitting an antifragile planning, from intersection repair ${ }^{4}$ to guerrilla way finding, ${ }^{5}$ from build a better block ${ }^{6}$ to pavement to plazas. ${ }^{7}$

All these questions deserve a much more detailed discussion, but let us focus on just one truly challenging aspect for the architects, engineers and planners: at the level of what we have called the space of the project, there are the basic constitutive elements, the "bricks" of an antifragile city: the buildings.

\section{The many lives of buildings, the building blocks of an antifragile city}

To build within the built space (Moneo 2007), and to begin from the many lives of the buildings (Rambert et al. 2015), is a fundamental path towards an antifragile planning for the great majority of European cities.

There is a lot to be learned and many ideas to be developed from the idea of shearing layers (Fig. 3), suggested by Frank Duffy, and further elaborated by Brand Stewart in his book How Building Learn. What Happens After They're Built (Stewart 1994) ${ }^{8}$; there is indeed a lot to learn from buildings that can learn.

Let us examine the six s-words in the figure. The thickness of the lines is indicative of the time different components of a building is expected to survive. The site is obviously the most durable: it is the place the building may in a way continue to exist even after it has disappeared. Follows the structure whose duration is remarkable, and which also can in a sense outlive the building itself. Next we have the building's wrapping, its skin, which quite like ours have many overlapping layers, frequently, sometimes even inadvertently, renewed and replaced. Then there are the services, which sometimes tightly follow the technological evolution, but sometimes lazily straggle and quaintly stuck in the past, even a remote one. Further we have the space plan, rapidly changing even without altering the actual internal

\footnotetext{
${ }^{4}$ See http://www.cityrepair.org/intersection-repair-examples/.

${ }^{5}$ See http://www.citylab.com/tech/2012/02/guerilla-wayfinding-raleigh/1139/.

6 See http://betterblock.org/how-to-build-a-better-block/.

7 See http://pavementtoplazas.com/.

8 Brand Stewart is not an architect, let alone a planner. He is rather what we may call an innovation surfer, but attentive to the long run, to the very long run; even literally: He is co-founder of the Long Now Foundation, http:// longnow.org/.
} 


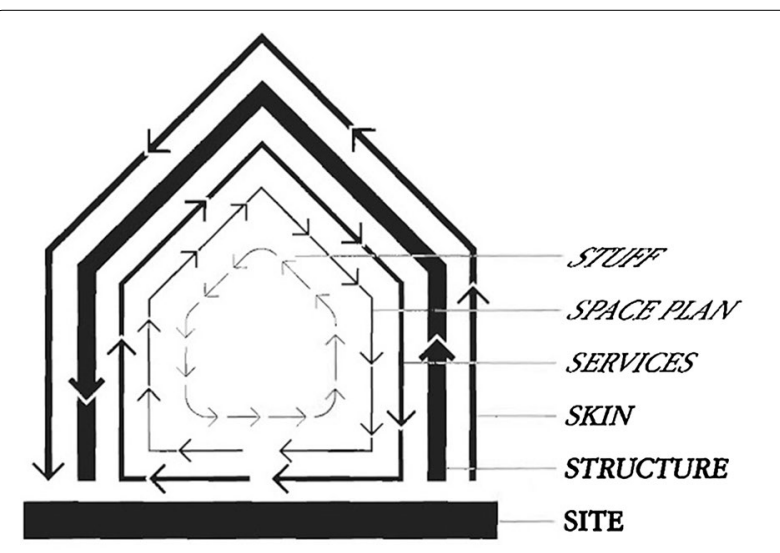

SHEARING LAYERS OF CHANGE. Because of the different rates of change of its components, a building is always tearing itself apart.

Fig. 3 The shearing layers of change [from Stewart (1994)]

distribution of spaces. And finally the stuff, some of which change swiftly within hours, day, or seasons.

\section{Site}

What could we possibly mean when we say that buildings may in a sense outlive their sites? To explain it we could say that this is in part the reason why philologically accurate reconstructions are built after a disaster has destroyed a building, a district, a city. A good example is the reconstruction of the St. Mark's Campanile in Venice after its collapse in 1902, under the motto "where it was, as it was". But that was only the most clamorous of a long series of interventions, restorations, substitutions and reconstructions of the campanile. The reconstruction on the same site and in the same form and material is a testimony of the "autonomous" life of buildings, of their being not only a constitutive part of the urbs, but also a founding elements of the civitas.

As Winston Churchill said: "We shape our buildings, and afterwards our buildings shape us. Having dwelt and served for more than 40 years in the late Chamber, and having derived very great pleasure and advantage there from, I, naturally, should like to see it restored in all essentials to its old form, convenience and dignity."

But there is more to it, in the fact that the form and the organisation of some buildings (and of some neighbourhoods) durably influence the site also through the new buildings that come to substitute them, in many often subtle and hardly perceptible ways.

\footnotetext{
${ }^{9}$ Churchill (1943) House of Commons (meeting in the House of Lords), 28 October 1943.
}

\section{Structure}

What we have just said is often particularly true for the building structure, frequently entirely or partially reused, and in other ways conditioning buildings that come to substitute the previous ones (as a sorts of "the phantom of the structure"): new structures lean on the old ones, often the successive accretions take over the original structures, sometimes the exaptations prevail over the structures that have generated them.

An old anecdote renders the idea of what we mean by "the phantom of the structure": a hammer is essentially composed of two parts: the handle and the head. Suppose you have an old hammer, a magnificent hammer with a decorated handle that belonged to your greatgreat-grandfather. With time the handle wears off, so you accept the service of a most excellent artisan who replaces the old with a new handle faithfully reproducing the original. Now on the wall you have a hammer hanging with the replaced handle. With time (maybe you have replaced a few more handles), perhaps the head's eye keeping the handle tight wears off, or the head rusts, and you are left with no options but also to replace it with a faithful reproduction. On the wall now graciously hangs your great-great-grandfather's hammer, in a way the original, even if no single molecule of this hammer is anymore the same.

\section{Skin}

The building's skin, its wrapping, is also capable to change and adapt. Even if it may often be renewed, it has also a degree of persistence, sometimes remarkably long, even if only for a shred of it. Indeed, those shreds are every so often the only lingering testimony of the original building.

But just as the human skin, it may change rather rapidly: indeed, the changes in the skin, first of all of its colour, often brings about a new image of the building: the classical architecture would no doubt reverberate differently in our minds without the lost of the original colour of their marbled skins.

\section{Services}

Even if becoming rapidly obsolete, dependent as they are on the evolution of technologies, the services can often also resist the time: in our times they are the most exposed to change, but sometimes the relative inefficiency of some of them is compensated by their great aesthetic (and affective) value.

\section{Space plan}

The distribution of spaces may for sure rapidly vary, but that is in many ways depending on the structure, on the site and on the services, so the freedom to rethink 
space plans is subjected to many constraints, even if frequently big changes in functions and uses are also possible through mere provisional, improvised, and reversible mutation of the plan. Some types of buildings are particularly fit for such an evolution, which can sometimes be obtained even simply through manipulating the stuff.

\section{Stuff}

The stuff, the furniture, the movables, change often anddepending on who uses them-their turnover may be fleeting and incessant. Yet there exists the propensity of some furniture to last, beyond the change of the people who live and use the spaces: they also become part of the building's aura, an element of its mutable life.

For all these reasons, for the combination of permanencies and transformations, more or less radical, more or less real or only perceived, we like to say that buildings are often antifragile-some buildings, under certain conditions.

What conditions? Learning from the scheme of the six s's, the main condition seems to be that the building ought in some way to have the predisposition to accommodate and embrace the requirement of different velocities of change, and to embrace it in the "right" way (in this sense, a perfect "anti-building", with an extremely rigid furniture and an utterly feeble structure and site, would be maximally fragile). In short, the building should be apt to adapt.

This feature may be the fruit of an unconscious learning (evolutionary, as in the solutions of the traditional architectures), or it may be the fruit of a conscious design wisdom.

The capability to adapt, and thus the survival of buildings, depends on this wisdom, on what we may call antifragile design proper.

\section{Conclusions}

As the history, and the history of architecture, teaches us, the survival of buildings is not a "question of style", but that of intelligence, organicity, adaptability-in short of antifragility-with which they were conceived and built. This is true for plenty of the contemporary architecture: no matter how much-dazzled by fashions, by the effervescence of the form, or by the futuristic technology-a building may appear to us extraordinary in all its novelty, its durable success ultimately hinges on its capability to create persistence, to age graciously, to learn and to embrace the unpredictable by adapting and improving with time.

This brings us back to Brand Stewart and his observation on old building:
Genuinely old buildings are constantly refreshed, but not too far, and new buildings are forced to ripen quickly. Hence the fashion in wood shingles, which weather handsomely in the course of a single winter. They are expensive and a fire hazard and will need replacing all too soon, but never mind.

The widespread fakery makes us respect honest aging all the more. The one garment in the world with the greatest and longest popularity-over a century nowis Levi's denim blue jeans. Along with their practical durability, they show age honestly and elegantly, as successive washing fade and shrink them to perfect fit and rich texture. Ingenious techniques to simulate aging of denim come and go, but the basic indigo 501s, copper-riveted, carry on for decades. This is highly evolved design. Are there blue-jeans buildings among us? How does design honestly honor time?

We admire the grand gesture in architecture, but we respect something else. In a computer teleconference on design, Brian Eno, the British rock musician and avant-garde artist, wrote:

"We are convinced by things that show internal complexity, that show the traces of an interesting evolution. Those signs tell us that we might be rewarded if we accord it our trust. An important aspect of design is the degree to which the object involves you in its own completion. Some work invites you into itself by not offering a finished, glossy, one reading only surface. This is what makes old buildings interesting to me. I think that humans have a taste for things that not only show that they have been through a process of evolution, but which also show they are still a part of one. They are not dead yet."

Between the dazzle of a new building and its eventual corpse, when it is either demolished or petrified for posterity as a museum, are the lost years-the unappreciated, undocumented, awkward-seeming time when it was alive to evolution. If Eno is right, those are the best years, the time when the building can engage us at our own level of complexity. (Stewart 1994, p. 11).

Jane Jacobs has also expressed with clarity the role of old buildings as a factor of urban quality:

Cities need old buildings so badly it is probably impossible for vigorous streets and districts to grow without them. By old buildings I mean not museumpiece old buildings, not old buildings in an excellent and expensive state of rehabilitation-although these make fine ingredients-but also a good lot of 
plain, ordinary, low-value old buildings, including some rundown old buildings.

If a city area has only new buildings, the enterprises that can exist there are automatically limited to those that can support the high costs of new construction. These high costs of occupying new buildings may be levied in the form of an owner's interest and amortization payments on the capital costs of the construction. However the costs are paid off, they have to be paid off. And for this reason, enterprises that support the cost of new construction must be capable of paying a relatively high overhead-high in comparison to that necessarily required by old buildings. To support such high overheads, the enterprises must be either (a) high profit or (b) well subsidized.

If you look about, you will see that only operations that are well established, high-turnover, standardized or heavily subsidized can afford, commonly, to carry the costs of new construction. Chain stores, chain restaurants and banks go into new construction. But neighborhood bars, foreign restaurants and pawn shops go into older buildings.... Wellsubsidized opera and art museums often go into new buildings. But the unformalized feeders of the artsstudios, galleries, stores for musical instruments and art supplies, backrooms where the low earning power of a seat and a table can absorb uneconomic discussions-these go into old buildings. Perhaps more significant, hundreds of ordinary enterprises, necessary to the safety and public life of streets and neighborhoods, and appreciated for their convenience and personal quality, can make out successfully in old buildings, but are inexorably slain by the high overhead of new construction.

As for really new ideas of any kind-no matter how ultimately profitable or otherwise successful some of them might prove to be-there is no leeway for such chancy trial, error and experimentation in the highoverhead economy of new construction. Old ideas can sometimes use new buildings. New ideas must use old buildings (Jacobs 1961, p. 187-188).

A perfect conclusion. True, antifragility is a property of systems, and it is not given that all the components of a system must be antifragile in order for the system to be antifragile.

But the city is a peculiar kind of system: a social system with two essential components, its buildings and its people; and we hold that it is necessary to care for, and take care of, the antifragility of them both. Buildings designed and built to last, to evolve and capable to accommodate new functions and new uses, are an important factor of urban antifragility.

On people, we shall return.

Authors' contributions

This paper is the fruit of a decade-long common research, explorations and discussions between the authors. Individual contributions are undisentanglable. Both authors read and approved the final manuscript.

\section{Author details}

${ }^{1}$ Department of Civil and Environmental Engineering and Architecture, University of Cagliari, Via Marengo 2, 09123 Cagliari, Italy. ${ }^{2}$ Department of Architecture, Design and Planning, University of Sassari, Piazza Duomo 6, 07041 Alghero, Italy.

\section{Competing interests}

The authors declare that they have no competing interests.

Received: 6 October 2016 Accepted: 20 December 2016

Published online: 25 January 2017

\section{References}

Ansar A, Flyvbjerg B, Budzier A, Lunn D (2016) Big is Fragile: an attempt at theorizing scale. In: Flyvbjerg B (ed) The Oxford handbook of megaproject management, Oxford University Press, Oxford. http://ssrn.com/ abstract $=2741198$

Blečić I, Cecchini A (2008) Design beyond complexity: possible futures-prediction or design? (and techniques and tools to make it possible). Futures 40(6):537-551

Blečić l, Cecchini A (2016) Verso una pianificazione antifragile. Come pensare al futuro senza prevederlo, FrancoAngeli, Milano

Bonomi A, Masiero R (2014) Dalla smart city alla smart land. Marsilio, Padova

Caragliu A, Del Bo C, Nijkamp P (2009) Smart cities in Europe. J Urban Technol 18(2):65-82

Cecchini A (2013) A great work: renovatio urbis in the age of globalization. In: Maciocco G, Johansson M, Serreli S (eds) City project. Springer, Public Space

Churchill W (1943), Speech on 28 October 1943, House of Commons

Crouch C (2004) Post-democracy. Polity Press, Cambridge

Diamond J (2005) Collapse: how societies choose to fail or succeed. Viking Press, New York

Greenfield A (2013) Against the Smart City. Do Projects, New York

Harvey D (2008) The right to the city. New Left Rev 53

Hemment D, Townsend A (eds) (2013) Smart citizens. Future Everything Publications, Manchester

Jacobs J (1961) The death and life of Great American Cities. Random House, New York

Koolhas R (2014) My thoughts on the smart city by Rem Koolhaas, edited transcript of a talk given at the High Level Group meeting on Smart Cities, Brussels. http://ec.europa.eu/archives/commission_2010-2014/ kroes/en/content/my-thoughts-smart-city-rem-koolhaas.html. Accessed 24 Sept 2014

Lydon M, Garcia A (2015) Tactical urbanism. Short-term action for long-term change. Island Press, Washington

Moneo R (2007) Costruire nel costruito. Allemandi, Torino

Musco F, Zanchini E (eds) (2014) II clima cambia le città. Strategie di adattamento e mitigazione nella pianificazione urbanistica. FrancoAngeli, Milano

Pickett STA, Cadenasso ML, Grove JM (2004) Resilient cities: meaning, models, and metaphor for integrating the ecological, socio-economic, and planning realms. Landsc Urban Plan 69:369-384

Portugali J, Meyer H, Stolk E (2012) Complexity theories of cities have come of age. Springer, Berlin

Radović D, Boontharm D, Kuma K, Grgić A (eds) (2012) The split case: density, intensity, resilience. Flick Studio, Tokyo 
Rambert F, Colombet M, Carboni C (2015) Un batiment combien de vies/La transformation comme acte de Creation. Silvana Editoriale, Milano

Ratti C (2013) Smart city, smart citizen. Egea, Milano

Rosanvallon P (2006) La contre-démocratie. La politique à l'âge de la défiance. Seuil, Paris

Stewart B (1994) How building learn. What happens after they're built. Penguin, London

Taleb N (2012) Antifragile. things that gain from disorder. Random House, New York
UK Government (2013) Smart Cities: background paper, Dept. for Business Innovation and Skills. https://www.gov.uk/government/publications/ smart-cities-background-paper

Wolfe CR (2012) What the history of Diocletian's Palace can teach us about adaptive reuse, Citylab (The Atlantic). http://www.citylab.com/ design/2012/02/what-history-diocletians-palaces-can-teach-us-aboutadaptive-reuse/1152/. Accessed 7 Feb 2012

\section{Submit your manuscript to a SpringerOpen ${ }^{\circ}$} journal and benefit from:

- Convenient online submission

- Rigorous peer review

- Immediate publication on acceptance

- Open access: articles freely available online

- High visibility within the field

- Retaining the copyright to your article

Submit your next manuscript at $\boldsymbol{\nabla}$ springeropen.com 